Article

\title{
Physical Activity Patterns in Adults who are Deaf
}

\author{
José Marmeleira ${ }^{1 *}$, Luís Laranjo ${ }^{2}$, Jorge Bravo ${ }^{3}$ and Diogo Menezes 4 \\ Received: 20 $0^{\text {th }}$ August 2018; Accepted: 14 ${ }^{\text {th }}$ February 2019; Published: $6^{\text {th }}$ April 2019
}

\begin{abstract}
The benefits of physical activity for health are well known, but there is limited information about its patterns in some disability groups. The main purpose of this study was to measure physical activity in a sample of adults who are Deaf. Sixty-two Deaf adults (18-65 years) from both genders (64.3\% women) participated. Physical activity was measured by accelerometers worn near the right hip for at least three days. Twenty-nine ( 59\%) of the 49 participants that met the accelerometer criteria reached the recommendation of $30 \mathrm{~min}$ per day of moderate-to-vigorous PA. However, no one achieved that goal in bouts of at least 10 minutes. Participants spent $71 \%$ of the accelerometer wear time in sedentary behaviour. It seems that hearing impairment has a lower impact on physical activity habits than other types of disability. Nonetheless, the levels of physical activity could be improved among the Deaf community, especially considering the international recommendations that aerobic activities should be performed in bouts of at least 10 minutes. Future research should collect information on the main barriers and facilitators for physical activity in adults who are Deaf, and strategies should be implemented to promote their engagement in longer bouts of physical activity.
\end{abstract}

Keywords: hearing impairment; sedentary behaviour; accelerometry; disability

\section{Introduction}

Research has shown that the regular practice of physical activity is associated with several health benefits, including the reduction of the risk of diabetes mellitus, colon cancer, breast cancer, coronary heart disease and stroke (Garber et al., 2011; Kyu et al., 2016). There is also strong evidence that physical activity has a positive impact on cognitive functioning and is associated with a lower risk of neurocognitive disorders (Marmeleira, 2013).

Traditionally the recommendations of physical activity for health purposes have stressed the relevance of engaging regularly in moderate and vigorous intensity physical activity (Garber et al., 2011; National Health Service, 2015; World Health Organization, 2004). For instance, in its Global Strategy on Diet, Physical Activity and Health, the World Health Organization (2004) recommends that adults should engage in at least $30 \mathrm{~min}$ of moderate-intensity physical activity most days of the week.

There is also growing evidence on health benefits of reducing the time spent in sedentary behaviour, that is in any waking behaviour characterized by an energy expenditure $\leq 1.5$ metabolic equivalents [METs] while in a sitting or reclining posture (Sedentary Behaviour Research Network, 2012). It has been shown that sedentary behaviour has an independent effect on overall morbidity and mortality (Keadle, Conroy, Buman, Dunstan, \& Matthews, 2017). One should note that increasing the time spent on moderate to vigorous physical activity (MVPA) does not necessarily imply a reduction in sedentary behaviour (Wanigatunga et al., 2017).

For promoting health-enhancing physical activity, it is fundamental to have updated data of the population's physical activity levels and to know the prevalence of people reaching the minimum levels of physical activity recommended for health benefits (Breda et al., 2018). Under an inclusion framework, such surveillance should involve all groups of the population, including the elderly and people with disabilities. The identification of specific population groups at risk due to poor physical 
activity habits should lead to the implementation of proper policy formulation and planning interventions for promoting active lifestyles (US Department of Health Human Services, 2005).

Presently, the information on the sedentary behaviour and physical activity of people with disabilities is relatively scarce, as they are rarely included in large-scale population studies. Nevertheless, the available information points that people with motor, visual or intellectual disabilities have low physical activity levels and high levels of sedentary behaviour (Dairo, Collett, Dawes, \& Oskrochi, 2016; Marmeleira, Laranjo, Marques, \& Pereira, 2014; Rocchi et al., 2017; Ryan, Forde, Hussey, \& Gormley, 2015).

Although it is estimated that $5 \%$ of the population worldwide have disabling hearing loss (World Health Organization, 2017), currently there is little information about their physical activity and sedentary behaviour patterns. Nevertheless, the scarce data that is available suggests that people with deafness or hearing loss are not sufficiently active and consequently are at a greater risk of health problems (Loprinzi, Smit, Lin, Gilham, \& Ramulu, 2013). In a study that included 67 Deaf adults, it was reported that women and men performed an average of 5,667 and 6,548 steps per day (Pelton, 2013), which differs substantially from the general 10,000 steps per day recommendation for healthy adults (Tudor-Locke \& Bassett, 2004). Nonetheless, it is important to note that general population studies have shown that most people do not achieve the recommendation of 10,000 steps per day (e.g., Colley et al., 2011).

Reliable information on the physical activity habits and sedentary behaviour of people with hearing impairment would help to guide the development of future policies and strategies to promote health-related behaviours in this specific group. Therefore, the main aim of this study is to examine by accelerometry the habitual physical activity and sedentary behaviour of Portuguese adults who are Deaf. In addition, this study investigates whether factors such as gender, chronological age, and body mass index (BMI) are associated with physical activity in adults who are Deaf.

\section{Materials and Methods}

\section{Design and Participants}

This was an observational study in which weekly physical activity and sedentary behaviour data were collected by accelerometer (model GT1M; Actigraph, Fort Walton Beach, FL). The inclusion criteria consisted of being Deaf with a severe to profound hearing loss, being 18-65 years of age, not having health problems preventing from engaging in exercise, and use the Portuguese Sign Language as the first form of communication. Information regarding the severity of hearing loss was obtained directly from the participants. We use Deaf (with a capital " $\mathrm{D}$ ") to indicate membership of the sign language using community.

Of the 62 adults who met the inclusion criteria and agreed to participate, 13 were excluded from the analysis as they did not fulfil with the accelerometer criteria (described in the instruments section). The descriptive characteristics of the 49 volunteers meeting the inclusion criteria are listed in Table 1. Fifteen participants (30.6\%) reported regularly performing some type of exercise, thirtyfive participants $(71.4 \%)$ reported not hearing any sound.

Table 1. Mean (standard deviations) of sample characteristics and t-test between genders

\begin{tabular}{lcccc}
\hline Characteristics & Men $(\mathrm{n}=17)$ & Women $(\mathrm{n}=32)$ & All $(\mathrm{n}=49)$ & $\mathrm{p}$ \\
\hline Age (years) & $43.7(13.0)$ & $43.0(14.6)$ & $43.2(13.9)$ & 0.862 \\
Height $(\mathrm{cm})$ & $168.8(6.3)$ & $155.5(6.9)$ & $160.0(16.8)$ & 0.001 \\
Weight $(\mathrm{kg})$ & $77.6(18.1)$ & $65.6(14.7)$ & $69.8(16.8)$ & 0.016 \\
Body Mass Index $\left(\mathrm{kg} / \mathrm{m}^{2}\right)$ & $27.6(6.9)$ & $27.6(6.3)$ & $27.6(6.5)$ & 0.976 \\
Education (years) & $9.1(5.0)$ & $9.3(4.6)$ & $9.2(4.7)$ & 0.860 \\
\hline
\end{tabular}


The objectives of the study were described to the participants and they all gave their informed consent to participate. The study was approved by the ethics committee of University of Évora and was conducted in compliance with the Declaration of Helsinki on Human Research.

\section{Procedures}

Three Portuguese associations for the Deaf (two from the city of Lisbon and one from the city of Évora) were invited and agreed to participate in this research. Afterwards, the associates that use regularly the association's facilities were contacted personally by the board of directors or by the researchers. For those who manifested their interest in participating, two visits were scheduled to the association's facilities. In the first visit, the participants fulfilled a socio-demographic questionnaire and a physical activity habits questionnaire and were instructed in the use of the accelerometer. The second visit took place approximately one week later and was used to collect the accelerometers. The communication with the participants was facilitated by the presence of a sign language interpreter. Data collection took place between March and July 2014.

\section{Instruments}

The assessment of physical activity and sedentary time was performed by accelerometry (ActiGraph GT1M model; Fort Walton Beach, Florida), set to record at 15-second epochs. Participants were instructed to wear the monitor attached on the right hip, near the iliac crest, for at least seven consecutive days during waking hours (except during water activities). For inclusion in the statistical analysis it was required that participants wore the accelerometer for $\geq 10$ hours per day during $\geq 3$ days, including 1 weekend day (Craig et al., 2003). Periods $\geq 60$ consecutive minutes of zero counts were considered non-wear time. The cut-off points used were: $<100$ counts for sedentary behaviour, 100-2,019 for light physical activity, 2,020-5,998 for moderate physical activity, and $\geq 5,999$ counts per minute for vigorous physical activity (Baptista et al., 2012; Marmeleira et al., 2014; Troiano et al., 2008). To examine adherence to physical activity recommendations for public health, we considered the accumulation of $\geq 30 \mathrm{~min}$ of moderate to vigorous physical activity (MVPA) per day (World Health Organization, 2004). Data were downloaded using ActiGraph software and processing performed with the program MAHUffe (http://www.mrc-epid.cam.ac.uk/physical-activitydownloads).

\section{Data analysis}

Data were checked for normality and homogeneity of variance using Shapiro-Wilk and Levene tests, respectively. Independent sample $t$-test was used to compare physical activity and sedentary behaviour between men and women. The associations of physical activity and sedentary behaviour data with age and BMI were analysed using Pearson's correlation. The Chi-square test was used to compare the percentage of participants who achieved the recommended levels of physical activity by gender. Data are presented as percentages, means, standard deviations, and 95\% confidence intervals. All statistical analyses were performed using IBM SPSS Statistics (version 19.0 SPSS Inc, Chicago, IL, USA). For all statistical tests, significance was set up at $p<.05$.

\section{Results}

The mean values and the confidence intervals for the physical activity variables measured by accelerometer are presented in Table 2. For the 49 participants, the number of valid days of accelerometer use ranged between 3 and 10 days (the average was $6.9 \pm 1.4$ days). On average participants spent $203.8 \mathrm{~min}$ per day in light physical activity and $38.7 \mathrm{~min}$ per day in MVPA (moderate, $38.3 \mathrm{~min}$ per day, vigorous $0.4 \mathrm{~min}$ per day). Most of accelerometer time use was spent in sedentary behaviour, which occurred in average 9.9 hours per day $(71 \%$ of the accelerometer wear time). The participants completed an average of $300( \pm 118)$ counts per minute and $8,078( \pm 2,913)$ steps per day. 
Table 2. Mean (standard deviation) of physical activity by accelerometer and t-test between genders

\begin{tabular}{lcccc}
\hline & Men $(N=17)$ & Women $(N=32)$ & All $(N=49)$ & $p$ \\
\hline Days with valid data (number) & $6.8(1.5)$ & $6.9(1.4)$ & $6.9(1.4)$ & .693 \\
Wear time (h/day) & $13.8(1.6)$ & $14.0(1.6)$ & $13.9(1.6)$ & .744 \\
Sedentary behaviour (h/day) & $9.6(1.6)$ & $10.1(1.8)$ & $9.9(1.7)$ & .371 \\
Light PA (min/day) & $204.6(45.0)$ & $203.3(65.8)$ & $203.8(58.9)$ & .944 \\
Moderate PA (min/day) & $51.1(29.8)$ & $31.5(16.3)$ & $38.3(23.6)$ & .020 \\
Vigorous PA (min/day) & $0.9(1.6)$ & $0.2(0.2)$ & $0.4(1.0)$ & .093 \\
Total PA (min/day) & $256.5(55.5)$ & $235.0(71.8)$ & $242.5(66.8)$ & .289 \\
Average PA (counts/min) & $356.2(135.8)$ & $270.4(96.5)$ & $300.2(117.8)$ & .014 \\
Steps per day (number) & $9326(3494)$ & $7415(2351)$ & $8078(2913)$ & .054 \\
\hline
\end{tabular}

Note. $p$ values for comparisons between genders; PA = physical activity.

In comparison with women, men performed more minutes of moderate physical activity (51.1 and $31.5 \mathrm{~min}$ per day for men and women, respectively) and at greater intensity (356.2 and 270.4 counts per min for men and women, respectively). Over half of the participants ( $n=29)$ complied with physical activity recommendations of $30 \mathrm{~min}$ per day of physical activity, when counting all minutes spent in moderate to greater physical activity level, as observed in Figure 1. Chi-square test showed that there was not a statistically significant difference $\left(\chi^{2}(1, n=49)=1.402, p=.236\right)$ between the proportion of men and women $(70.6 \%$ and $53.1 \%$, respectively) that achieved the recommended levels of physical activity. When one examines only the daily peiods of 10 or more continuous minutes spent in MVPA and not the sum of all minutes spent in moderate or greater physical activity, none of the participants accumulated $30 \mathrm{~min}$ of MVPA per day.

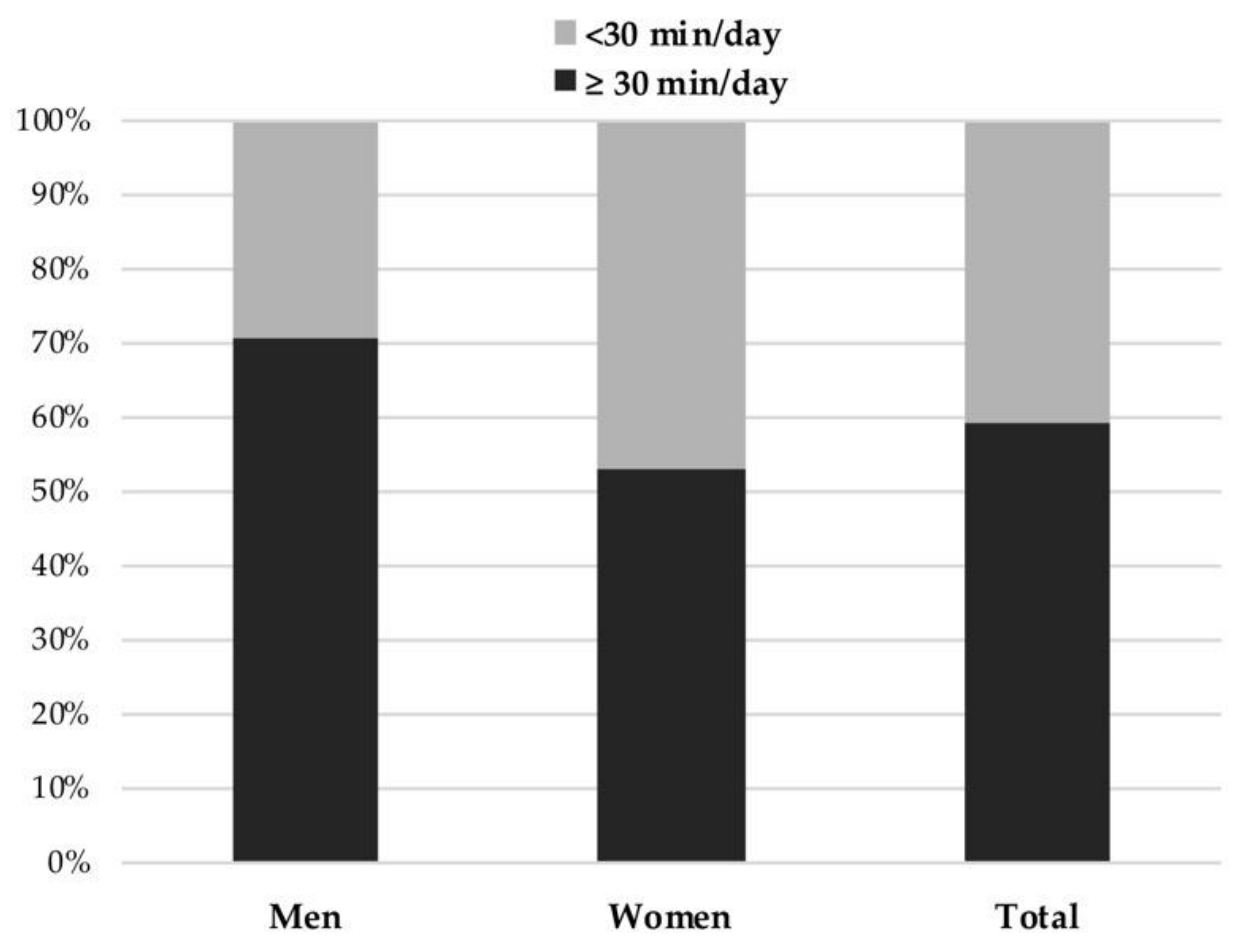

Figure 1. Proportion of participants who accumulated at least $30 \mathrm{~min}$ per day of moderate to vigorous physical activity.

Pearson's correlation (Table 3) showed that age and BMI were not associated with physical activity data. The average BMI of the participants was $27.6 \pm 6.46 \mathrm{~kg} / \mathrm{m}^{2}$ and in-depth analysis showed that $37 \%$ of the participants were overweight (BMI $25-30 \mathrm{~kg} / \mathrm{m}^{2}$ ) and $27 \%$ were obese (BMI $\left.30 \mathrm{~kg} / \mathrm{m}^{2}\right)$. 
Table 3. Correlations of age and BMI with physical activity and sedentary behaviour.

\begin{tabular}{ccccccc}
\hline & Light PA & MVPA & Total PA & Steps & $\begin{array}{c}\text { Average } \\
\text { PA }\end{array}$ & $\begin{array}{c}\text { Sedentary } \\
\text { Behaviour }\end{array}$ \\
\hline Age & .01 & -.082 & -.02 & .01 & -.13 & .28 \\
BMI & .01 & -.172 & -.06 & -.16 & .00 & -.08 \\
\hline
\end{tabular}

Note. $\mathrm{PA}=$ Physical Activity; $\mathrm{BMI}=$ Body Mass Index; MVPA= Moderate to Vigorous Physical Activity.

\section{Discussion}

To our knowledge, this is the first study to evaluate objectively physical activity and sedentary behaviour of adults who are Deaf. Thus, 49 participants used an accelerometer for a significant period of time (on average, almost 7 valid days of measurement were obtained per participant). Our results showed that when counting all minutes spent in MVPA, approximately six out of ten participants accumulated on average at least $30 \mathrm{~min}$ of MVPA per day. The prevalence of physical activity found in the current study is lower than that reported before by Baptista et al. (2012) for the general Portuguese adult population, which $70 \%$ of adults aged between 18-64 years engaged in sufficient amounts of MVPA ( $\geq 30 \mathrm{~min}$ of MVPA per day). Both studies reported similar average daily values of MVPA: $40 \mathrm{~min}$ per day for the general adult population and $39 \mathrm{~min}$ per day for adults who are Deaf. The same trend was evident for the average intensity of PA: 330 counts per min in the study of Baptista et al. (2012) and 300 counts per min in the present study. One should note that the average daily step count achieved by the participants in the current study $(8,078 \pm 2,913)$ was below the general 10,000 steps per day recommendation for healthy adults (Tudor-Locke \& Bassett, 2004). However, previous investigations also showed that most of the general population did not achieve this recommendation (Bento, Romero, Leitão, \& Mota, 2014; Colley et al., 2011). Regarding walking behaviour, it is important that future studies also examine specific variables (e.g., cadence steps/min) related with physical activity intensity due to their potential relevance to health (TudorLocke et al., 2018).

Regarding sedentary behaviour, Baptista et al. (2012) reported data for the general Portuguese adult population stratified for 10 years to 15 years age groups, showing values between $8.8 \mathrm{~h}$ and 9.9 $\mathrm{h}$ per day, which is in line with the average time $(9.9 \mathrm{~h})$ that the participants of our study spent in sedentary behaviour. The Deaf adults that participated in the present study spent approximately $71 \%$ of the accelerometer wear time in sedentary behaviour, which is very close to the $69 \%$ of sedentary behaviour previously reported for the general Canadian adult population (Colley et al., 2011). These data strengthen the idea that the participants of our study have patterns of physical activity and sedentary behaviour relatively similar to the general population.

Unfortunately, there is limited research on physical activity and sedentary behaviour in adults with hearing impairment. In one of the few studies about this issue conducted in the United Sates, it was reported that people with moderate to higher hearing loss performed on average only $20 \mathrm{~min}$ per day of MVPA, staying below the recommendations (Loprinzi et al., 2013). Other reports also in the United States, concluded that adults aged 65 and older with moderate or greater hearing loss engage in more sedentary behaviour than their counterparts with hearing within normal limits (Loprinzi, 2013). One should note that the latter study did not report descriptive data on physical activity and sedentary behaviour. In an unpublished dissertation (Pelton, 2013) that used pedometers to evaluate physical activity in Deaf adults, it was reported an average number of steps per day of 5,667 , which is well below the 8,078 steps per day found in the current study, although in the study by Pelton (2013) the participants were older (average of 61.8 years) than in the present study (average of 43.2 years).

In comparison with other types of sensory impairment, namely visual impairment, the participants in the current study are much more active, which can be confirmed for instance from the results of a study also conducted in Portugal which showed that only $30 \%$ of adults with visual impairment reached the $30 \mathrm{~min}$ per day recommendation of MVPA (Marmeleira et al., 2014). The comparison with people with intellectual disability is even much more favorable, as a recent systematic review concluded that only $9 \%$ of adults with such type of disability achieved the 
minimum physical activity guidelines (Dairo et al., 2016). Previous research with children and youth also showed that Deaf people are more active than those with physical disabilities, intellectual impairment or visual impairment (Longmuir \& Bar-Or, 2000; Ng, Rintala, Tynjälä, Villberg \& Kannas, 2014; Suzuki et al., 1991) and there is evidence that motor competence of youths with hearing impairments is relatively similar to their peers without a hearing impairment (Goodman \& Hopper, 1992).

Our results suggest that hearing impairment has a lower impact on physical activity habits than other types of disability. Probably, some of the main barriers for physical activity pointed by people who have a visual or a physical disability do not have the same impact in people who are Deaf. This could be the case of prevalent physical activity barriers as the need for a guide, the risk of falls and collisions, physical health, or the difficulties with accessibility and transport (Jaarsma, Dijkstra, Geertzen, \& Dekker, 2014; Legood, Scuffham, \& Cryer, 2002; Vissers et al., 2008). Nevertheless, in order to raise the physical activity levels in people who are Deaf it is important that future studies point which are the main personal and environmental barriers and facilitators for physical activity among the Deaf community. For instance, it was reported that Deaf people may have difficulty in accessing health information and that such lack of information can influence their decisions regarding a healthier lifestyle (Emond et al., 2015; McKee et al., 2011; Rimmer \& Rowland, 2008). The understanding of how this applies particularly to the decision of people who are Deaf engaging in physical activity might be very helpful to find strategies of how to get the message across for promoting physical activity.

In the current study, none of the participants complied with the recommendation of $30 \mathrm{~min}$ per day of MVPA when considering only the periods of 10 or more continuous minutes spent in MVPA along the day (and not the sum of all minutes spent in moderate or greater intensity). This is in line with previous studies (Baptista et al., 2012; Hagströmer, Oja, \& Sjöström, 2007) and indicate that physical activity of moderate intensity or greater is frequently performed in short periods and/or are often interrupted, which is common in some structured activities (e.g., sports) and not structured activities (e.g., domestic activities). As most recommendations of PA for adults stress the importance of engaging in periods of MVPA of at least 10 minutes (Garber et al., 2011; National Health Service, 2015; World Health Organization, 2010), it is important to examine in the future the reasons why Deaf adults tend to engage in small episodes of PA. Nevertheless, one should take into account that some recent studies have provided evidence that significant health and quality of life benefits could be achieved even if MVPA is accumulated in episodes shorter than $10 \mathrm{~min}$ (Jefferis et al., 2018; Loprinzi, 2015). Among other health contributions, small periods of MVPA may help to breakdown prolonged sedentary behaviour, which has emerged as an independent indicator of health status (Loprinzi, 2015). The 2018 Physical Activity Guidelines for Americans recently released by the US Department of Health and Human Services (2018) also acknowledge that bouts of any length contribute to the health benefits associated with the accumulated volume of physical activity. This position is based on evidence from observational studies of cardiometabolic risk factors using accelerometer-measured physical activity, and not self-report measures of physical activity as in the past.

Our study corroborates previous findings from general population surveys (including Portugal) of higher physical activity in men compared with women (Baptista et al., 2012; Hagströmer, Troiano, Sjöström, \& Berrigan, 2010) and is in line with the only study with adults that are Deaf (Pelton, 2013) that, to our knowledge, compared physical activity between genders, and reported 6,548 and 5,044 steps per day for men and women, respectively. Similar results were found in adults with intellectual disability (Barnes, Howie, McDermott, \& Mann, 2013) but not in people who are blind (Marmeleira et al., 2014).

Chronological age was not associated with physical activity. Conversely, the study of Pelton (2013) reported a small $(r=-.289)$ yet significant correlation between age and the number of steps in Deaf adults. Nevertheless, the fact that the participants of that study were older (45-75+ years) than those of the current study (18-65 years), could have had some influence in the results as it is well known that older adults tend to engage in lower levels of physical activity than their young counterparts (Baptista et al., 2012; Troiano et al., 2008). The higher number of female participants 
$(65.3 \%)$ in the current study could also have been related to the absence of associations between physical activity and age as it was reported previously that within the age range of 18-65 years the association of lower physical activity prevalence with increasing age is much more evident for males than for women (Bauman et al., 2009).

The average BMI $\left(27.6 \pm 6.5 \mathrm{~kg} / \mathrm{m}^{2}\right)$ was above the cut-off level for being overweight. In fact, about two thirds of the participants were overweight $\left(37 \%\right.$ BMI $\left.25-30 \mathrm{~kg} / \mathrm{m}^{2}\right)$ or obese $(27 \%$ BMI $>30$ $\mathrm{kg} / \mathrm{m}^{2}$ ) which is in line with a previous study in the UK which reported using the same BMI criteria that $41 \%$ and $30 \%$ of the Deaf participants were overweight or obese, respectively (Emond et al., 2015). BMI was not related to physical activity behaviour. One should note that previous general population-based studies did not provide evidence for the role of BMI in physical activity patterns (Baptista et al., 2012; Troiano et al., 2008), or reported contradictory results (Hagströmer et al, 2007; Tian et al., 2016). Also, there is little information of the role of BMI in physical activity and sedentary patterns in people with disability. Marmeleira et al. (2014) in their study of adults who are visually impaired, did not find an association between BMI and physical activity, while others (Oviedo, Travier, \& Guerra-Balic, 2017) reported that obese adults with intellectual disability spent more time in sedentary behaviour than their counterparts with a normal BMI.

This study had some limitations. First, we used a relatively small and convenient sample, and future studies should enrol a higher number of participants to confirm present findings. Secondly, participants were volunteers attending associations for Deaf people, which may have resulted in a sample biased toward being more active than the general people who are Deaf. The same type of bias could have occurred due to the fact that 13 participants initially enrolled in the study did not meet the accelerometer criteria. Finally, the fact that the level of severity of hearing loss was not objectively evaluated constituted another limitation, although all participants confirmed that their hearing was absent (or was very limited) and use Portuguese Sign Language as their first language.

\section{Perspective}

Physical activity has emerged as a fundamental factor for health and well-being and based on scientific evidence. A number of national and international organizations have proposed physical activity guidelines. This research expands the current knowledge on the physical activity behaviour of people with disabilities, adding relevant information about adults who are Deaf. It provides evidence that the physical activity levels of adults who are Deaf, although lower than those of the general population, are not so affected as for other disability groups. Although a considerable proportion $(\sim 59 \%)$ of Deaf adults accumulate periods of moderate to vigorous physical activity that are in accordance with the general physical activity guidelines, there are still a significant number of people that do not engage in sufficient physical activity; This group should be the main focus of health promoters and practitioners in the future. Also, the present study showed that the volume of MVPA is accumulated in bouts bellow 10 minutes. The current findings should prompt researchers to look carefully at the barriers and facilitators of physical activity in Deaf adults, and specifically for the reasons why they tend to engage in short episodes of physical activity.

\section{Conclusion}

In conclusion, our findings showed that six out of ten participants reached the health recommendation of $30 \mathrm{~min}$ of MVPA. However, MVPA was performed in short periods over the day, while most physical activity guidelines recommend bouts of MVPA $\geq 10 \mathrm{~min}$. Participants spent about ten hours of their $14 \mathrm{hr}$ of accelerometer wear time in sedentary behaviour. The members of the Deaf community seem to be almost as active as the general Portuguese adult population. It was found that men are more physically active than women, but age and BMI are not associated with physical activity. Finally, it seems that a great proportion of adults from the Deaf community are overweight.

\section{Authors Affiliations:}

1 Departamento de Desporto e Saúde, Escola de Ciências e Tecnologia, Universidade de Évora, Portugal; geral@ddes.uevora.pt; Comprehensive Health Research Centre, Évora, Portugal; novasaude@unl.pt; 
Research Centre in Sports Sciences, Health Sciences and Human Development, CIDESD, Portugal; cidesd.geral@utad.pt

2 Departamento de Desporto e Saúde, Escola de Ciências e Tecnologia, Universidade de Évora, Portugal; geral@ddes.uevora.pt; Research Centre in Sports Sciences, Health Sciences and Human Development, CIDESD, Portugal; cidesd.geral@utad.pt

3 Departamento de Desporto e Saúde, Escola de Ciências e Tecnologia, Universidade de Évora, Portugal; geral@ddes.uevora.pt;

4 Departamento de Desporto e Saúde, Escola de Ciências e Tecnologia, Universidade de Évora, Portugal; geral@ddes.uevora.pt;

* Correspondence: jmarmel@uevora.pt; Tel.: +351- 266769522

Author Contributions: Conceptualization, JM, LL and DM; Methodology, JM, LL and DM; Writing-Original Draft Preparation, JM and DM; Writing-Review \& Editing, JM, LL, DM and JB.

Funding: This research received no external funding

Acknowledgments: The authors are grateful by the support provided by the Deaf Association of Évora, by the Portuguese Deaf Association and the Deaf and Cultural Association of Amadora. No financial support was provided for this study. The authors report no conflicts of interest.

Conflicts of Interest: The authors declare no conflict of interest.

\section{References}

Baptista, F., Santos, D. A., Silva, A. M., Mota, J., Santos, R., Vale, S., . . Sardinha, L. B. (2012). Prevalence of the Portuguese population attaining sufficient physical activity. Medicine and Science in Sports and Exercise, 44(3), 466-473. doi:10.1249/MSS.0b013e318230e441

Barnes, T. L., Howie, E. K., McDermott, S., \& Mann, J. R. (2013). Physical activity in a large sample of adults with intellectual disabilities. Journal of Physical Activity \& Health, 10(7), 1048-1056. doi:10.1123/jpah.10.7.1048

Bauman, A., Bull, F., Chey, T., Craig, C. L., Ainsworth, B. E., Sallis, J. F., . . Pratt, M. (2009). The international prevalence study on physical activity: results from 20 countries. International Journal of Behavioral Nutrition and Physical Activity, 6(1), 21. doi:10.1186/1479-5868-6-21

Bento, T. C., Romero, F., Leitão, J. C., \& Mota, M. P. (2014). Portuguese adults' physical activity during different periods of the year. European Journal of Sport Science, 14(sup1), S352-S360. doi:10.1080/17461391.2012.704081

Breda, J., Jakovljevic, J., Rathmes, G., Mendes, R., Fontaine, O., Hollmann, S., . . Galea, G. (2018). Promoting health-enhancing physical activity in Europe: Current state of surveillance, policy development and implementation. Health Policy, 122(5), 519-527. doi:10.1016/j.healthpol.2018.01.015

Colley, R. C., Garriguet, D., Janssen, I., Craig, C. L., Clarke, J., \& Tremblay, M. S. (2011). Physical activity of Canadian adults: accelerometer results from the 2007 to 2009 Canadian Health Measures Survey. Health Reports, 22(1), 7-14.

Craig, C. L., Marshall, A. L., Sjostrom, M., Bauman, A. E., Booth, M. L., Ainsworth, B. E., . . Oja, P. (2003). International physical activity questionnaire: 12-country reliability and validity. Medicine and Science in Sports and Exercise, 35(8), 1381-1395. doi:10.1249/01.MSS.0000078924.61453.FB

Dairo, Y. M., Collett, J., Dawes, H., \& Oskrochi, G. R. (2016). Physical activity levels in adults with intellectual disabilities: A systematic review. Preventive Medicine Reports, 4, 209-219. doi:10.1016/j.pmedr.2016.06.008

Emond, A., Ridd, M., Sutherland, H., Allsop, L., Alexander, A., \& Kyle, J. (2015). The current health of the signing Deaf community in the UK compared with the general population: a cross-sectional study. British Medical Journal, 5 (e006668). doi:10.1136/bmjopen-2014-006668

Garber, C. E., Blissmer, B., Deschenes, M. R., Franklin, B. A., Lamonte, M. J., Lee, I., . . Swain, D. P. (2011). Quantity and quality of exercise for developing and maintaining cardiorespiratory, musculoskeletal, and neuromotor fitness in apparently healthy adults: Guidance for prescribing exercise. Medicine and Science in Sports and Exercise, 43(7), 1334-1359. doi:10.1016/j.pmedr.2016.06.008

Goodman, J., \& Hopper, C. (1992). Hearing impaired children and youth: A review of psychomotor behavior. Adapted Physical Activity Quarterly, 9(3), 214-236. doi:10.1123/apaq.9.3.214

Hagströmer, M., Oja, P., \& Sjöström, M. (2007). Physical activity and inactivity in an adult population assessed by accelerometry. Medicine and Science in Sports and Exercise, 39(9), 1502-1508. doi:10.1249/mss.0b013e3180a76de5

Hagströmer, M., Troiano, R. P., Sjöström, M., \& Berrigan, D. (2010). Levels and patterns of objectively assessed physical activity - a comparison between Sweden and the United States. American Journal of Epidemiology, 171(10), 1055-1064. doi:10.1093/aje/kwq069 
Jaarsma, E. A., Dijkstra, P. U., Geertzen, J. H., \& Dekker, R. (2014). Barriers to and facilitators of sports participation for people with physical disabilities: a systematic review. Scandinavian Journal of Medicine $\mathcal{E}$ Science in Sports, 24(6), 871-881. doi:10.1111/sms.12218

Jefferis, B. J., Parsons, T. J., Sartini, C., Ash, S., Lennon, L. T., Papacosta, O., . . Whincup, P. H. (2018). Objectively measured physical activity, sedentary behaviour and all-cause mortality in older men: does volume of activity matter more than pattern of accumulation? British Journal of Sports Medicine, 0, 1-8. Published Online First. doi: 10.1136/bjsports-2017-098733

Keadle, S. K., Conroy, D. E., Buman, M. P., Dunstan, D. W., \& Matthews, C. E. (2017). Targeting reductions in sitting time to increase physical activity and improve health. Medicine and Science in Sports and Exercise, 49(8), 1572-1582. doi:10.1249/MSS.0000000000001257

Kyu, H. H., Bachman, V. F., Alexander, L. T., Mumford, J. E., Afshin, A., Estep, K., . . Forouzanfar, M. H. (2016). Physical activity and risk of breast cancer, colon cancer, diabetes, ischemic heart disease, and ischemic stroke events: systematic review and dose-response meta-analysis for the Global Burden of Disease Study 2013. British Medical Journal, 354, i3857. doi:10.1136/bmj.i3857

Legood, R., Scuffham, P., \& Cryer, C. (2002). Are we blind to injuries in the visually impaired? A review of the literature. Injury Prevention, 8(2), 155-160. doi:10.1136/ip.8.2.155

Longmuir, P. E., \& Bar-Or, O. (2000). Factors influencing the physical activity levels of youths with physical and sensory disabilities. Adapted Physical Activity Quarterly, 17(1), 40-53. doi:10.1123/apaq.17.1.40

Loprinzi, P. D. (2015). Accumulated short bouts of physical activity are associated with reduced premature allcause mortality: Implications for physician promotion of physical activity and revision of current US government physical activity guidelines. Mayo Clinic Proceedings, 90(8), 1168-1169. doi:10.1016/j.mayocp.2015.06.008

Loprinzi, P. D. (2013). Association between accelerometer-assessed sedentary behavior and objectivelymeasured hearing sensitivity in older US adults. Preventive Medicine, 57(2), 143-145. doi:10.1016/j.ypmed.2013.05.007

Loprinzi, P. D., Smit, E., Lin, F. R., Gilham, B., \& Ramulu, P. Y. (2013). Accelerometer-assessed physical activity and objectively determined dual sensory impairment in US adults. Mayo Clinic Proceedings, 88(7), 690-696. doi:10.1016/j.mayocp.2013.04.008

Marmeleira, J. (2013). An examination of the mechanisms underlying the effects of physical activity on brain and cognition. European Review of Aging and Physical Activity, 10(2), 83-94. doi:10.1007/s11556-012-0105-5

Marmeleira, J., Laranjo, L., Marques, O., \& Pereira, C. (2014). Physical activity patterns in adults who are blind as assessed by accelerometry. Adapted Physical Activity Quarterly, 31(3), 283-296. doi:10.1123/apaq.2013-0039

McKee, M., Schlehofer, D., Cuculick, J., Starr, M., Smith, S., \& Chin, N. P. (2011). Perceptions of cardiovascular health in an underserved community of deaf adults using American Sign Language. Disability and Health Journal, 4(3), 192-197. doi:10.1016/j.dhjo.2011.04.001

National Health Service (2015). Physical activity guidelines for adults. Retrieved from https://www.nhs.uk/Livewell/fitness/Pages/physical-activity-guidelines-for-adults.aspx

$\mathrm{Ng}$, Rintala, Tynjälä, Villberg, \& Kannas (2014). Physical activity patterns of adolescents with long-term illnesses or disabilities in Finnish general education. European Journal of Adapted Physical Activity, 7(1), 58-72. doi:10.5507/euj.2014.005

Oviedo, G. R., Travier, N., \& Guerra-Balic, M. (2017). Sedentary and physical activity patterns in adults with intellectual disability. International Journal of Environmental Research and Public Health, 14(9), E1027. doi:10.3390/ijerph14091027

Pelton, D. K. (2013). Evidence-Based Plan for Promoting Physical Activity Among Deaf Adults in Primary Care. (Doctoral Electronic Dissertation), The University of Arizona, Retrieved from http://hdl.handle.net/10150/311571

Rimmer, J. H., \& Rowland, J. L. (2008). Health promotion for people with disabilities: Implications for empowering the person and promoting disability-friendly environments. American Journal of Lifestyle Medicine, 2(5), 409-420. doi:10.1177/1559827608317397

Rocchi, M., Routhier, F., Latimer-Cheung, A. E., Ginis, K. A. M., Noreau, L., \& Sweet, S. N. (2017). Are adults with spinal cord injury meeting the spinal cord injury-specific physical activity guidelines? A look at a sample from a Canadian province. Spinal Cord, 55(5), 454-459. doi:10.1038/sc.2016.181

Ryan, J. M., Forde, C., Hussey, J. M., \& Gormley, J. (2015). Comparison of patterns of physical activity and sedentary behavior between children with cerebral palsy and children with typical development. Physical Therapy, 95(12), 1609-1616. doi:10.2522/ptj.20140337

Sedentary Behaviour Research Network (2012). Letter to the editor: Standardized use of the terms "sedentary" and "sedentary behaviours". Applied Physiology, Nutrition, and Metabolism, 37(3), 540-542. doi:10.1139/h2012024 
Suzuki, M., Saitoh, S., Tasaki, Y., Shimomura, Y., Makishima, R., \& Hosoya, N. (1991). Nutritional status and daily physical activity of handicapped students in Tokyo metropolitan schools for deaf, blind, mentally retarded, and physically handicapped individuals. The American Journal of Clinical Nutrition, 54(6), 11011111.

Tian, Y., Jiang, C., Wang, M., Cai, R., Zhang, Y., He, Z., . . McNaughton, L. R. (2016). BMI, leisure-time physical activity, and physical fitness in adults in China: results from a series of national surveys, 2000-14. The Lancet Diabetes \& Endocrinology, 4(6), 487-497. doi:10.1016/S2213-8587(16)00081-4

Troiano, R. P., Berrigan, D., Dodd, K. W., Masse, L. C., Tilert, T., \& McDowell, M. (2008). Physical activity in the United States measured by accelerometer. Medicine and Science in Sports and Exercise, 40(1), 181-188. doi:10.1249/mss.0b013e31815a51b3

Tudor-Locke, C., \& Bassett, D. R., Jr. (2004). How many steps/day are enough? Preliminary pedometer indices for public health. Sports Medicine, 34(1), 1-8.

Tudor-Locke, C., Han, H., Aguiar, E. J., Barreira, T. V., Schuna Jr, J. M., Kang, M., \& Rowe, D. A. (2018). How fast is fast enough? Walking cadence (steps/min) as a practical estimate of intensity in adults: a narrative review. British Journal of Sports Medicine, 52(12), 776-788. doi:10.1136/bjsports-2017-097628

US Department of Health and Human Services (2005). The Surgeon General's call to action to improve the health and wellness of persons with disabilities. Retrieved from https://www.ncbi.nlm.nih.gov/books/NBK44667/

US Department of Health and Human Services (2018). 2018 Physical Activity Guidelines Advisory Committee Scientific Report. Retrieved from https://health.gov/paguidelines/secondedition/report/pdf/PAG_Advisory_Committee_Report.pdf

Vissers, M., van den Berg-Emons, R., Sluis, T., Bergen, M., Stam, H., \& Bussmann, H. (2008). Barriers to and facilitators of everyday physical activity in persons with a spinal cord injury after discharge from the rehabilitation centre. Journal of Rehabilitation Medicine, 40(6), 461-467. doi:10.2340/16501977-0191

Wanigatunga, A. A., Ambrosius, W. T., Rejeski, W. J., Gill, T. M., Glynn, N. W., Tudor-Locke, C., \& Manini, T. M. (2017). Association between structured physical activity and sedentary time in older adults. JAMA, 318(3), 297-299. doi:10.1001/jama.2017.7203

World Health Organization (2017). Deafness and hearing loss. Retrieved from http://www.who.int/en/newsroom/fact-sheets/detail/deafness-and-hearing-loss

World Health Organization (2004). Global Strategy on Diet, Physical Activity and Health. Geneva: World Health Organization.

World Health Organization (2010). Global recommendations on physical activity for health. Geneva: World Health Organization.

(c) 2018 by the authors. Submitted for possible open access publication under the terms and conditions of the Creative Commons Attribution (CC BY) license (http://creativecommons.org/licenses/by/4.0/) 